\title{
Improving Power Quality of Power System Using D-STATCOM
}

\author{
Anjali Gupta, Amit Kumar Tripathi
}

\begin{abstract}
In power system there are several types of losses which disturb whole of the electrical equipment installed in it. Therefore, it is required to pay more attention towards the improvement of power quality by minimizing the losses of power system. The present invention relates to the improvement of power quality of power system using distribution static compensator. For improving the power quality, the power system along with the distribution static compensator is designed in the MATLAB simulation and the result obtained after compensating the losses is shown in this paper.
\end{abstract}

Keywords- D-STATCOM, power system losses, power quality, reactive power.

\section{INTRODUCTION}

The vast power system comprises of a distribution transformer, circuit breaker, relays, current transformer, potential transformer, isolators and many more electrical equipment [1]. These electrical equipment causes different type of losses. And these losses effect the power quality by undergoing into short circuit fault, overcurrent fault, line to line fault and other transmission line faults [2],[3]. The overvoltage fault in the load side also disturbs the power quality of the distribution system.

In a power system there are basically three types of power swell and third is interruption [4].

Voltage Sag - The reduction in the voltage profile for the duration of one minute is known as voltage sag. It is caused due to the following reasons as mentioned below-

Causes- voltage sag is caused due to the switching of large power bank, starting of heavy loads and during overload condition.

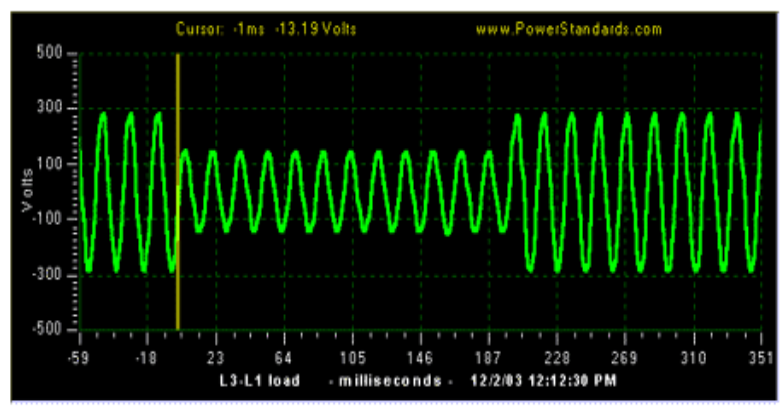

Revised Version Manuscript Received on 10 September, 2018.

Anjali Gupta, Associate Department of Electrical \& Electronics Engineering, Noida Institute of Engineering and Technology, Uttar Pradesh, India.

Amit Kumar Tripathi, Department of Electrical \& Electronics Engineering, Noida Institute of Engineering and Technology, Uttar Pradesh, India.

(Email: researchnietip@gmail.com) quality problem first is voltage sag and second is voltage

(Email: researchnietip@gmail.com)

Voltage Swell - The increment of voltage profile for the duration of one minute is known as voltage swell. The causes of voltage swell are mentioned below-

Causes- voltage swell is caused due to the switching off heavy loads, turning off the large capacitor bank and due to the lighting surges.

Interruption- when the terminal voltage decreases below the nominal value of voltage for short duration of time then it is known as supply interruption.

Causes- interruption of power supply are caused by malfunctioning of electrical equipment or circuit breaker $[5],[6]$.

\section{RMS Voltage Variations}

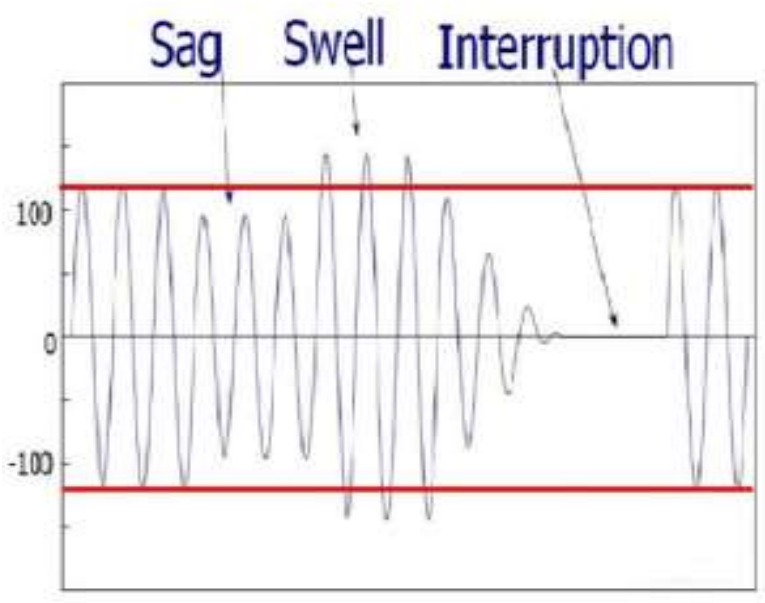

Thus, it is required to develop a device that is capable of improving such types of power quality problems in the power system. Hence, this paper proposes a D-STATCOM based device for improving the power quality.

\section{THEORY OF D-STATCOM}

Distribution static compensator (D-STATCOM) is a FACTS (flexible ac transmission system) based voltage source converter that provide a reactive power to the distribution system and maintains the power quality of the system [7]. The D-STATCOM is shunt connected device which comprises of a coupling transformer connected in between the distribution line and D-STATCOM device. The compensator is connected near to the load side so that if there is a need of reactive power to the load then this compensator 
could fulfil the need of reactive power [8]. Thus, it can be

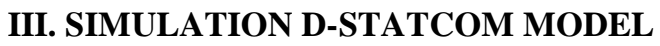
said that the distribution static compensator is a device that injects reactive power when needed and thereby improving the power quality of the power system.
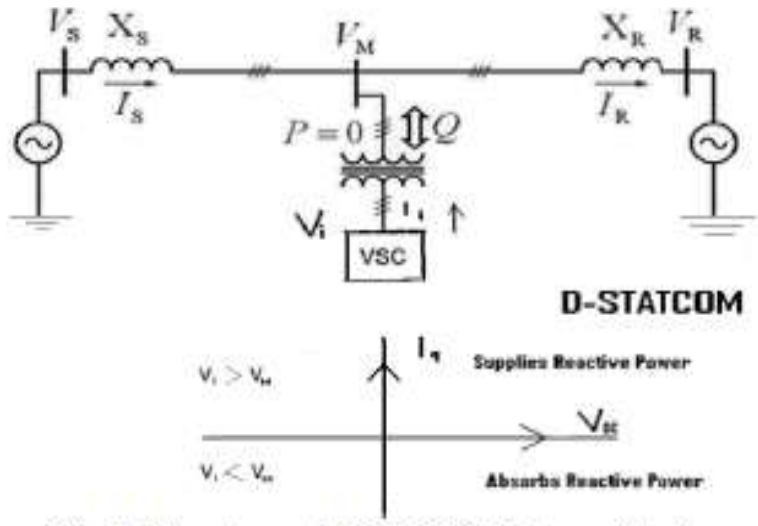

Fig. 1: Structure of DSATCOM along with its operational mode

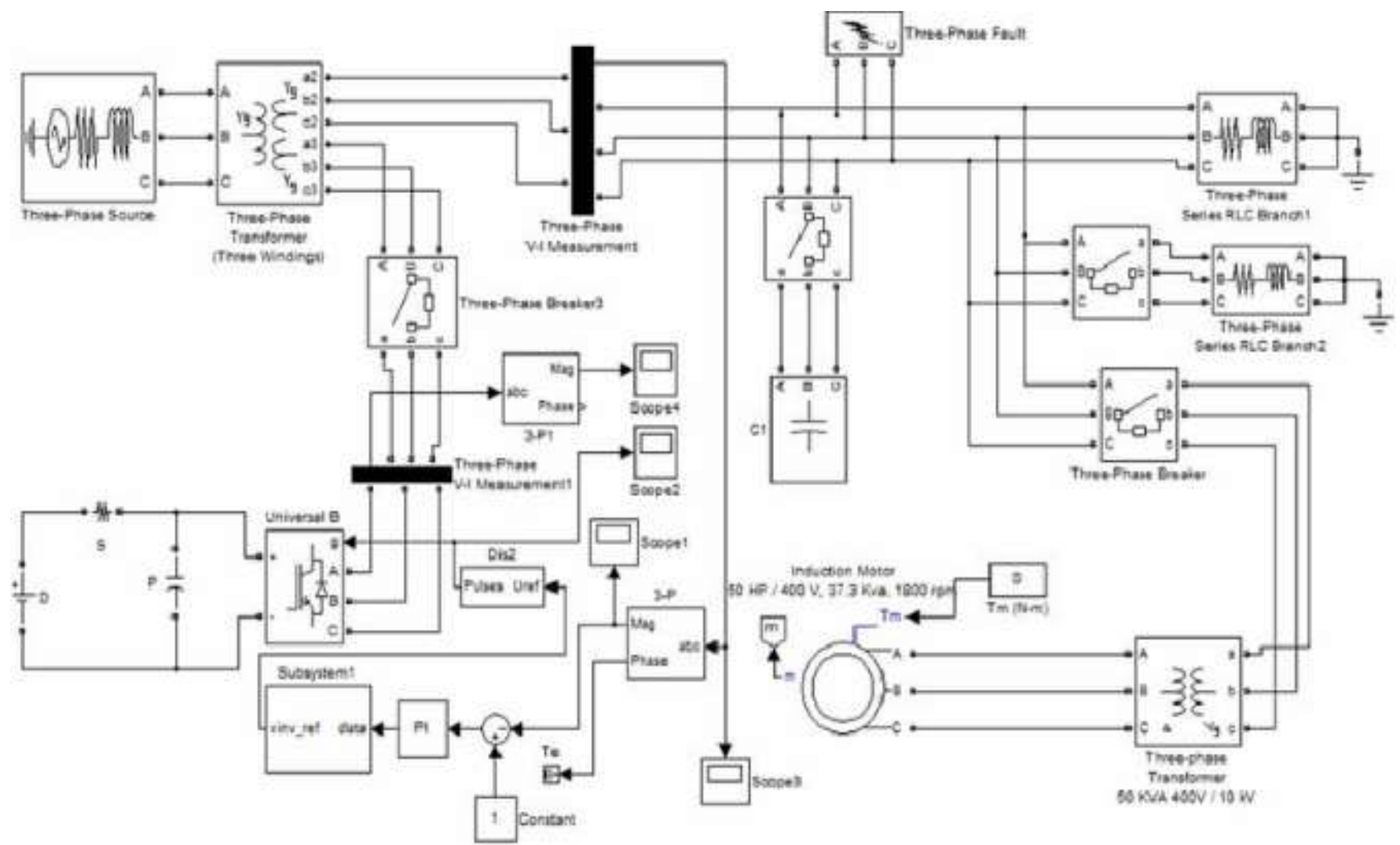

Fig.2 Simulation Model of Power System using D-STATCOM

Fig. 2 represents the simulation model of power system using D-STATCOM. In this simulation the three phase transformer is used for supplying three phase power. The three-phase fault generator block is inserted near the load side for generating fault condition, the D-STATCOM is connected in shunt to distribution system and activates when it senses any fault near the load side. Distribution static compensator is voltage source converter that provide reactive power to the load side when the there is any decrement in reactive power at load side. The parameters of simulation model is shown in below tables- 
Table l: Parameters for different parts of test system

\begin{tabular}{|c|c|}
\hline Block & Parameter \\
\hline 3 phase source & $\begin{array}{l}\text { Ph to ph rms voltage }=25000 \mathrm{~V} \text {, frequency }=50 \mathrm{~Hz} z \\
\text { source resistance }=8929 \Omega, \\
\text { inductance }=01656 \mathrm{H}\end{array}$ \\
\hline $\begin{array}{l}3 \text { phase } \\
\text { transformer ( } 3 \\
\text { winding) }\end{array}$ & Measurement-winding voltage \\
\hline $\begin{array}{l}3 \text { phase series } \\
\text { RLC load } 1\end{array}$ & $\begin{array}{l}\text { Nominal ph to ph voltage }=11000 \mathrm{~V} \text {,Nominal } \\
\text { frequency }=50 \mathrm{~Hz} \text {, Active } \\
\text { power }=1000 \mathrm{~kW} \text {.reactive power }=20 \mathrm{VAR}\end{array}$ \\
\hline 3 phase breaker & Resistance $=001 \Omega$, snubber resistance $=1 \mathrm{M} \Omega$ \\
\hline $\begin{array}{l}3 \text { phase series } \\
\text { RLC load }\end{array}$ & $\begin{array}{l}\text { Nominal ph to ph voltage }=11000 \mathrm{~V}, \text { Nominal } \\
\text { frequency }=50 \text { Hertz, active power }=10 \\
\mathrm{~kW}, \text { reactive power }=100 \mathrm{VAR}\end{array}$ \\
\hline
\end{tabular}

Table 2: Parameters for DSATCONI

\begin{tabular}{|l|l|}
\hline \multicolumn{1}{|c|}{ Blocks } & \multicolumn{1}{|c|}{ Parameter } \\
\hline $\begin{array}{l}\text { 3 phase } \\
\text { transformer(12 } \\
\text { terminal) }\end{array}$ & $\begin{array}{l}\text { 3 ph rated power }=11 \mathrm{~kW}, \text { frequency }=50 \mathrm{~Hz}, \\
\text { magnetizing branch } \mathrm{Rm}=10 \Omega, \mathrm{Xm}=10 \Omega\end{array}$ \\
\hline PI controller & Proportional gain $=5$, Integral gain $=120$ \\
\hline Capacitance & $\mathrm{C}=750 \mu \mathrm{F}$ \\
\hline $\mathrm{DC}$ voltage source & Amplitude $=2400 \mathrm{~V}$ \\
\hline Universal bridge & $\begin{array}{l}\text { Number of bridge arms }=3, \text { Snubber } \\
\text { resistance }=50000 \Omega\end{array}$ \\
\hline PWM generator & Carrier frequency $=375 \mathrm{HZ}$ \\
\hline
\end{tabular}

IV. MATLAB RESULTS

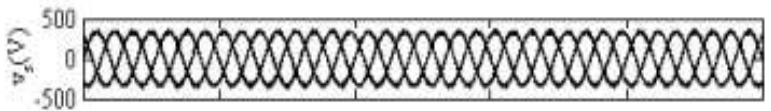

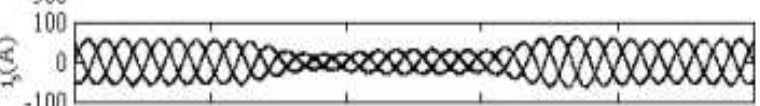
-100 , I ,

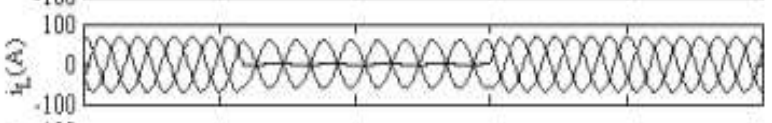

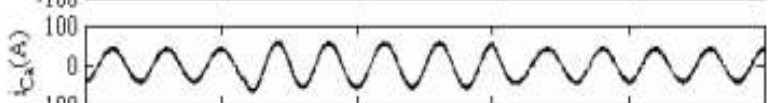
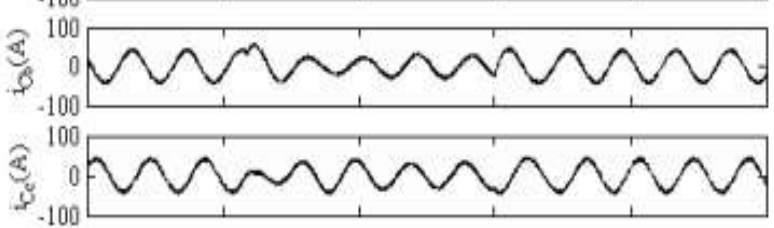

Fig.3 Dynamic Performance of D-STATCOM under varying load condition
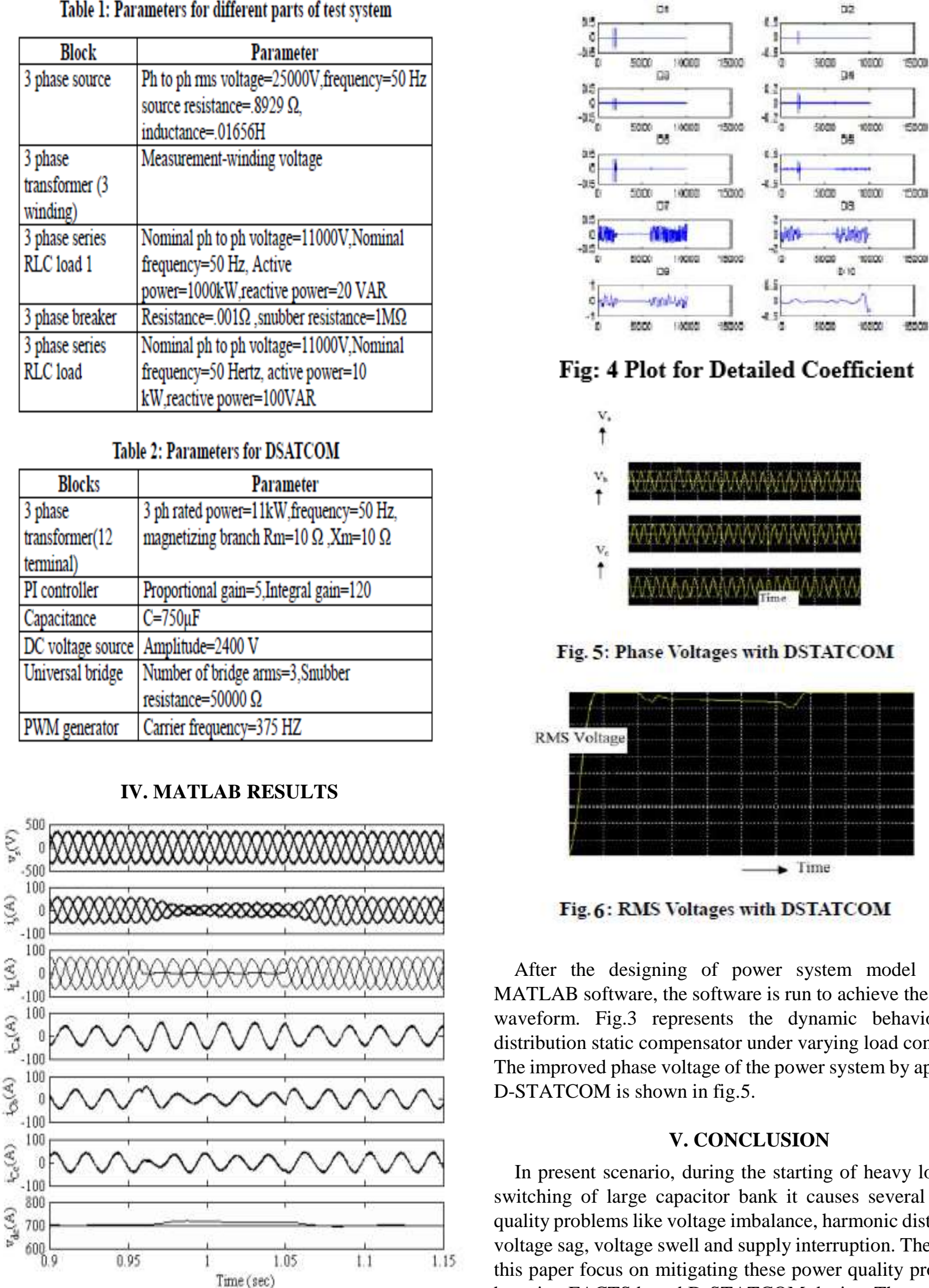

Fig: 4 Plot for Detailed Coefficient

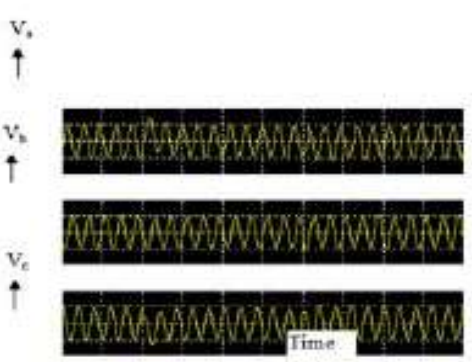

Fig. 5: Phase Voltages with DSTATCOM

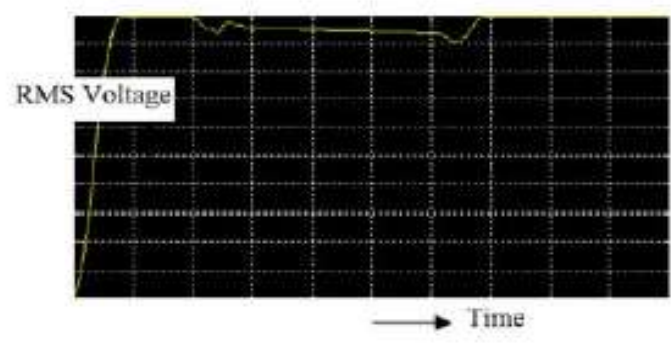

Fig. 6: RMS Voltages with DSTATCOM

After the designing of power system model in the MATLAB software, the software is run to achieve the output waveform. Fig.3 represents the dynamic behaviour of distribution static compensator under varying load condition. The improved phase voltage of the power system by applying D-STATCOM is shown in fig.5.

\section{CONCLUSION}

In present scenario, during the starting of heavy loads or switching of large capacitor bank it causes several power quality problems like voltage imbalance, harmonic distortion, voltage sag, voltage swell and supply interruption. Therefore, this paper focus on mitigating these power quality problems by using FACTS based D-STATCOM device. The complete experiment is performed in the MATLAB Simulink software by designing simulation model of power system using D-STATCOM and the output waveform is shown in result section. 


\section{REFERENCES}

1. M. Kezunovic, "Fundamentals of Power System Protection," in The Electrical Engineering Handbook, 2005.

2. S. Vasantharathna, "Electric power systems," in Electric Renewable Energy Systems, 2015.

3. A. T. Johns, "Protection," in Electrical Engineer's Reference Book: Sixteenth Edition, 2003.

4. M. H. Bollen, Understanding Power Quality Problems. 2010.

5. "Electrical power systems quality," Choice Rev. Online, 2013.

6. S. Rönnberg and M. Bollen, "Power quality issues in the electric power system of the future," Electr. J., 2016.

7. T. L. Lee, S. H. Hu, and Y. H. Chan, "D-STATCOM with positive-sequence admittance and negative-sequence conductance to mitigate voltage fluctuations in high-level fenetration of distributed-generation systems," IEEE Trans. Ind. Electron., 2013.

8. I. Scholar and E. Engineering, "Modeling and Simulation of a Distribution STATCOM (D-STATCOM) for Power Quality Problems- Voltage Sag and Swell Based on Sinusoidal Pulse Width Modulation (SPWM)," IEEE Int. Conf. Adv. Eng. Sci. Manag., 2012. 